\title{
Secondary hyperaldosteronism leading to resistant hypertension in a patient with adrenal Cushing's syndrome
}

\author{
I Ranathunga ${ }^{1}$, N P Somasundaram ${ }^{1}$ \\ ${ }^{1}$ Diabetes and Endocrinology unit, National Hospital of Sri Lanka.
}

\section{Abstract}

\section{Background}

Cushing's syndrome (CS) is a rare disorder caused by prolonged hypercortisolism leading to increased morbidity and mortality. Hypertension in Cushing's syndrome could be caused by multiple mechanism including primary hyperaldosteronism from cosecretion of aldosterone from the adrenal tumour, and rarely due to secondary hyperaldosteronism.

\section{Case presentation}

A-36-year old female with poorly controlled hypertension, dyslipidaemia and diabetes mellitus presented with progressive truncal obesity with marked abdominal distension. She also had proximal muscle weakness and oligomenorrhea. On examination, specific clinical features suggestive of Cushing's syndrome such as round face, facial plethora, truncal obesity with fat distribution in the face, neck, trunk, abdomen with sparing of the limbs, thin skin and proximal myopathy were present. Investigations confirmed the diagnosis of adrenocorticotrophic hormone independent adrenal Cushing's syndrome due to a left adrenal adenoma with secondary hyperaldosteronism. Subsequently, she underwent laparoscopic left adrenalectomy as the definitive management which resulted in good clinical outcome.

\section{Conclusions}

Secondary hyperaldosteronism can be a rare association of Cushing's syndrome and can contribute to resistant hypertension. Possible pathogenesis comprises of renin co-secretion, increased vascular responsiveness to vasopressor agents, increased renin levels leading to increased angiotensin 1 formation and possible interference of aldosterone action by steroids. Successful treatment of the primary pathology results in cure of the abnormality. (SJDEM 2020/ Vol 10/ No 2)

Key words: Cushing's syndrome, Secondary hyperaldosteronism, Adrenal Adenoma

Correspondence email: ish_75@yahoo.com

Orchid ID: https://orcid.org/0000-0002-2188-5309

Copyright: This is an open-access article distributed under the terms of the Creative Commons Attribution License, which permits unrestricted use, distribution, and reproduction in any medium, provided the original author and source are credited (CC BY 4.0)

\section{Introduction}

Prolonged exposure to elevated cortisol leads to development of Cushing's syndrome ${ }^{(1)}$. It is a rare disorder associated with increased morbidity and mortality(1). Primary hyperaldosteronism can be caused by co-secretion of aldosterone from the adrenal tumour( ${ }^{(2)}$. Rarely, secondary hyperaldosteronism has been reported(3)(4)(5)(6).
The mechanisms of secondary hyperaldosteronism are numerous and resolves by treating the primary disease. We report a case of Cushing's syndrome due to an adrenal adenoma who presented with resistant hypertension contributed by secondary hyperaldosteronism. 


\section{Case presentation}

A-36-year old female presented with hypertension and dyslipidaemia for four years and newly diagnosed diabetes mellitus for one month. Her blood pressure was poorly controlled with three antihypertensive drugs. She also had progressive truncal obesity with marked abdominal distension. In addition she had proximal muscle weakness and oligomenorrhea.

On examination, she had a round face with facial plethora. There was truncal obesity with predominant fat distribution in the face, neck, trunk, abdomen with sparing of the limbs. She had thin skin and proximal myopathy with grade 4 power on Medical Research Council (MRC) grading scale.

Her pulse rate was $92 \mathrm{bpm}$, pressure was 150/100 $\mathrm{mmHg}$. Her respiratory, abdominal and neurology examination was unremarkable. On investigation, she was found to have hypokaleamic alkalosis. She also had high baseline serum cortisol levels which remained unsuppressed with overnight dexamethasone suppression test (ODST), low dose dexamethasone suppression test (LDDST) and high dose dexamethasone suppression test (HDDST). Her adrenocorticotrophic hormone (ACTH) level was 2.5 $\mathrm{pg} / \mathrm{ml}$, indicating ACTH independent Cushing's syndrome.
Furthermore, her plasma aldosterone level was elevated (45.7 ng/dL) with unsuppressed renin activity of $5.99 \mathrm{ng} / \mathrm{ml} / \mathrm{hr}$ with a ratio of 7.6 which is suggestive of secondary hyperaldosteronism. To confirm secondary hyperaldosteronism, she underwent a saline loading test; the plasma aldosterone level suppressed to $1.25 \mathrm{ng} / \mathrm{dL}$. Her investigations summarized in Table 1 .

To look for a cause of ACTH independent Cushing's syndrome, she underwent non contrast enhanced computerized tomography (CT) scan of the abdomen. A $2.7 \mathrm{~cm}$ well defined mass in the left adrenal gland with density $32 \mathrm{HU}$ was found with radiological features suggestive of an adrenal adenoma. Right adrenal gland was normal (Figure1).

A diagnosis of ACTH independent adrenal Cushing's syndrome with secondary hyperaldosteronism was made and she was referred for laparoscopic surgery. While awaiting surgery she was started on oral ketoconazole to achieve optimal control of her cortisol levels. Subsequently she underwent successful left adrenalectomy (Figure 2, Figure 3).

Table 1: A Summary of Investigations

\begin{tabular}{llc}
\hline Investigation & Value & Reference Range \\
\hline Serum Sodium & $138 \mathrm{mmol} / \mathrm{L}$ & $135-148 \mathrm{mmol} / \mathrm{L}$ \\
Serum Potassium & $3.4 \mathrm{mmol} / \mathrm{L}$ & $3.5-5.1 \mathrm{mmol} / \mathrm{L}$ \\
Arterial blood pH & 7.49 & $7.35-7.45$ \\
Arterial blood HCO3 & $28 \mathrm{mEq} / \mathrm{L}$ & $22-26 \mathrm{mEq} / \mathrm{L}$ \\
Overnight dexamethasone suppression test (ODST) & $668.43 \mathrm{nmol} / \mathrm{L}$ & $<50 \mathrm{nmol} / \mathrm{L}$ \\
Low dose dexamethasone suppression test (LDDST) & $772.87 \mathrm{nmol} / \mathrm{L}$ & $<50 \mathrm{nmol} / \mathrm{L}$ \\
High dose dexamethasone suppression test (HDDST) & $826 \mathrm{nmol} / \mathrm{L}$ & $405 \mathrm{nmol} / \mathrm{L}$ \\
Adrenocorticotrophic hormone (ACTH) & $2.5 \mathrm{pg} / \mathrm{ml}$ & $7-41 \mathrm{pg} / \mathrm{ml}$ \\
Plasma aldosterone & $45.7 \mathrm{ng} / \mathrm{dL}$ & $3.47-27.5 \mathrm{ng} / \mathrm{dL}$ \\
Renin activity & $5.99 \mathrm{ng} / \mathrm{ml} / \mathrm{hr}$ & $0.6-4.18 \mathrm{ng} / \mathrm{ml} / \mathrm{hr}$ \\
Aldosterone/Renin ratio (ARR) & 7.6 & $<20$ \\
Post saline load test plasma aldosterone & $1.25 \mathrm{ng} / \mathrm{dL}$ & $<5 \mathrm{ng} / \mathrm{dL}$ \\
\hline
\end{tabular}




\begin{tabular}{llll}
\hline Fasting blood glucose & $4.7 \mathrm{mmol} / \mathrm{L}$ & $<7 \mathrm{mmol} / \mathrm{L}$ \\
HbA1c & $6.7 \%$ & $<6.5 \%$ \\
Lipid profile & $156 \mathrm{mg} / \mathrm{dL}$ & $<200 \mathrm{mg} / \mathrm{dL}$ \\
& Total Cholesterol & $229 \mathrm{mg} / \mathrm{dL}$ & $<150 \mathrm{mg} / \mathrm{dL}$ \\
Triglycerides & $49 \mathrm{mg} / \mathrm{dL}$ & $>50 \mathrm{mg} / \mathrm{dL}$ \\
HDL- Cholesterol & $61 \mathrm{mg} / \mathrm{dL}$ & $<100 \mathrm{mg} / \mathrm{dL}$ \\
LDL- Cholesterol & $107 \mathrm{mg} / \mathrm{dL}$ & $<130 \mathrm{mg} / \mathrm{dL}$ \\
\hline
\end{tabular}
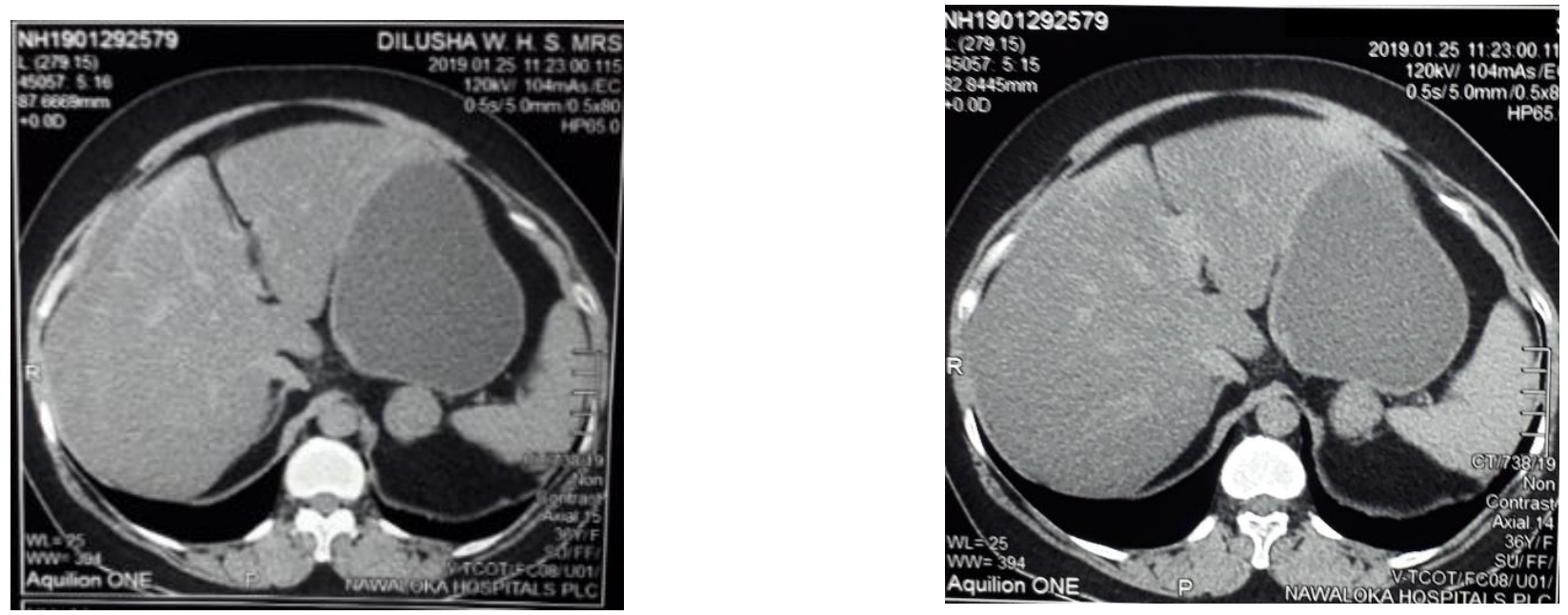

Figure 1: CT scan of the Abdomen and Pelvis

Both kidneys are normal in size and density. A $2.7 \mathrm{~cm}$ well defined mass in the left adrenal gland with a density of $32 \mathrm{HU}$ which is suggestive of an adrenal adenoma
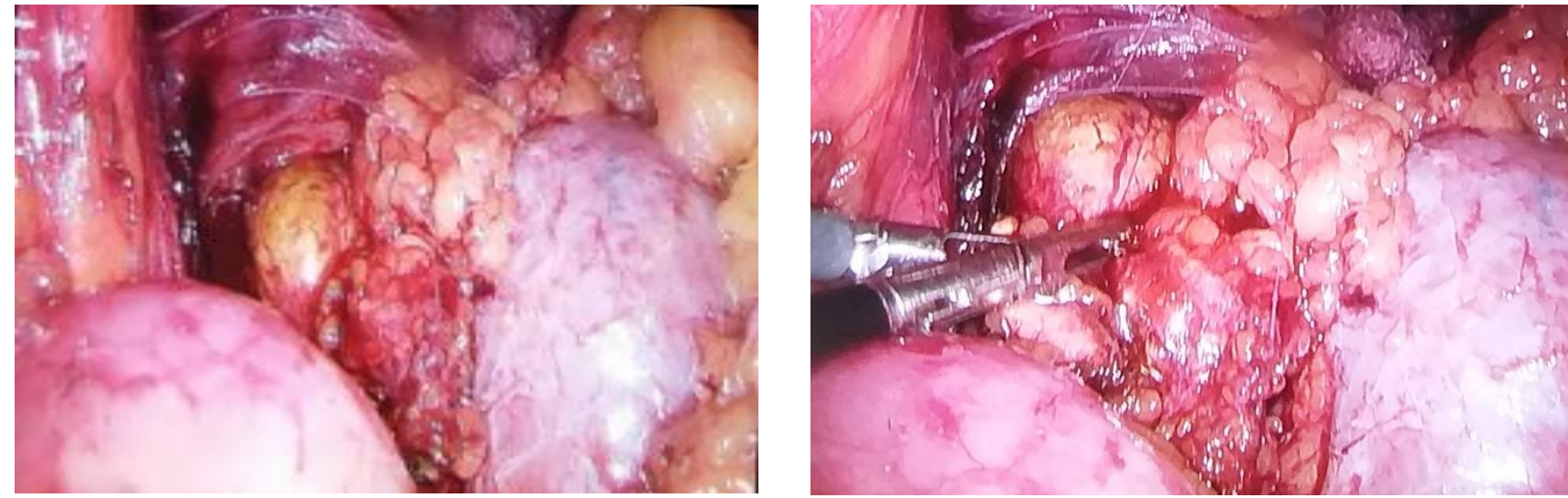

Figure 2: Laparoscopic appearance of the Left adrenal tumour 

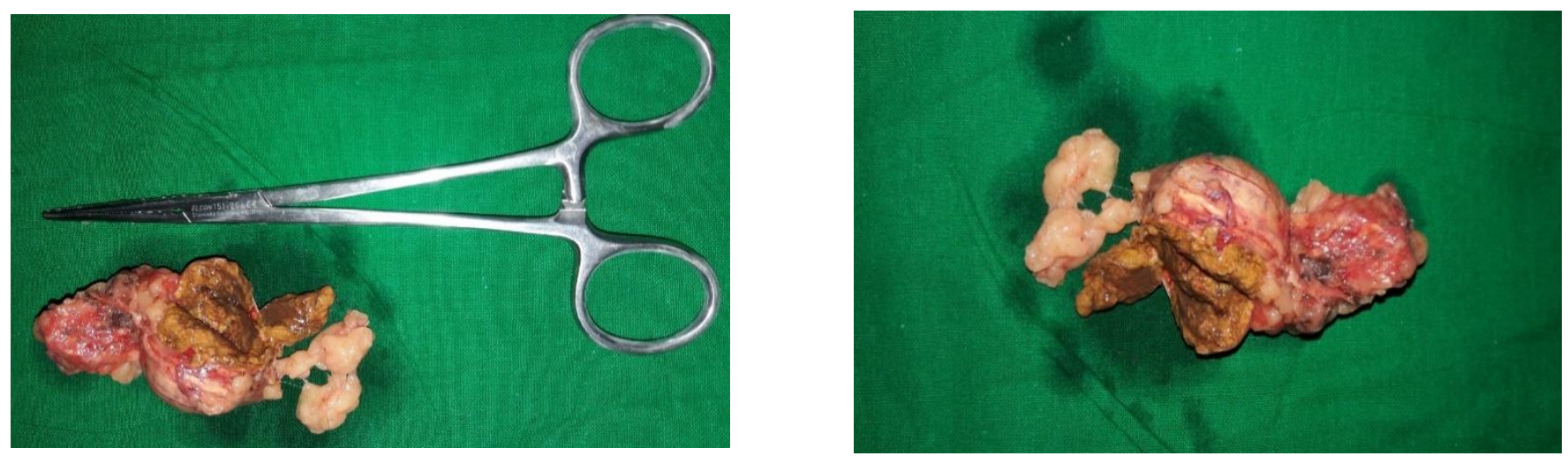

Figure 3: Macroscopic appearance of the left adrenal tumour after surgical resection
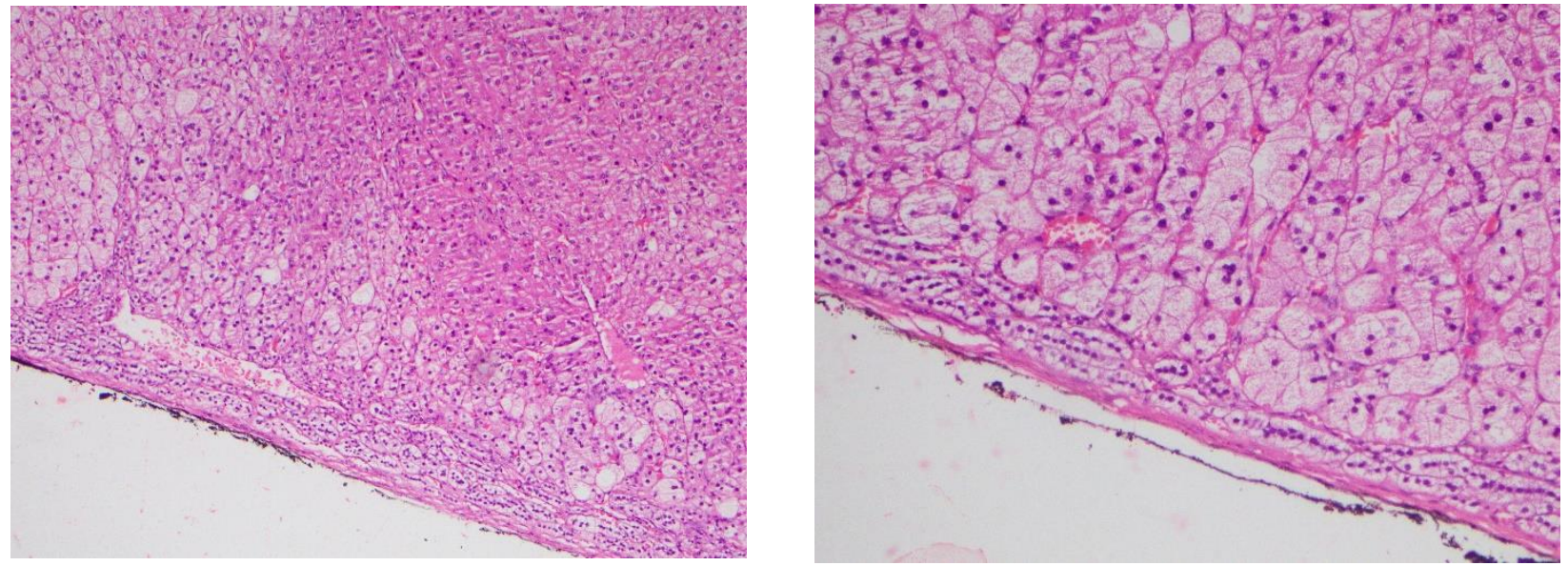

Figure 4: Histology

Sections show thinly encapsulated tumour with a peripheral discontinuous rim of thinned out adrenal parenchyma. The tumour comprises nests, islands, and fused traberculae of polygonal cells, with round uniform nuclei and fine chromatin. Many cells have abundant clear to pale cytoplasm while others have eosinophilic cytoplasm. Some cells have nucleoli and nuclear pseudo inclusions. Mitosis or necrosis are not seen. Capsular or vascular invasion is not present.

Conclusion-Adreno-cortical adenoma 
Histology demonstrated an adreno-cortical adenoma (Figure 4). Post operatively her blood glucose levels and blood pressure were normalized gradually and currently she is on tapering doses of oral hydrocortisone.

\section{Discussion}

Secondary hyperaldosteronism can be a rare association of Cushing's syndrome. Though Cushing's syndrome itself can be associated with hypertension, co-existing secondary hyperaldosteronism can lead to resistant hypertension. Here we have discussed a case of Secondary hyperaldosteronism who initially presented to us with resistant hypertension.

The pathophysiology contributing to the disease can be multiple and include renin co-secretion, increased vascular responsiveness to vasopressor agents, increased renin levels leading to increase angiotensin 1 formation by glucocorticoids and possible interference of aldosterone action by steroids. Renin secreting adrenal adenoma is a rare condition while cortisol and renin co-secretion is a theoretical possibility(3). Hyper-cortisolism leads to overproduction of the renin substrate by the liver which in turn increases Angiotensin 1 synthesis culminating in elevated blood pressure(4)(5). Furthermore, enhanced vascular responsiveness to vasopressor agents such as norepinephrine can lead to elevated renin levels ${ }^{(6)}$. Finally, cortisol may interfere with the aldosterone action which result in unsuppressed renin levels in the presence of elevated aldosterone concentration(2). Studies done on amphibia has demonstrated that both cortisol and corticosterone prevent aldosterone-stimulated sodium transport via competitive inhibition of aldosterone binding leading to failure of renin suppression (7).

Management of co-occurrence of secondary hyperaldosteronism with Cushing's syndrome can be challenging. Though the successful treatment of the primary pathology may alleviate the elevated blood pressure, while awaiting the definitive treatment, medical management may play an important role. Treatment of Cushing's syndrome due to cortisol secretion from an adrenal adenoma includes steroidogenesis inhibitors or glucocorticoid receptor antagonists ${ }^{(8)}$. The specific treatment of secondary hyperaldosteronism due to resistant hypertension in a Cushing's patient has not been extensively studied. Theoretically, the steroidogenesis inhibitors or glucocorticoid receptor antagonists can reduce the cortisol burden culminating in reduced production of the renin substrate by the liver, diminished vascular responsiveness to vasopressor agents and loss of competitive inhibition of aldosterone action(4)(5)(6)(7). Medical therapy with mineralocorticoid receptor (MR) antagonist is indicated in primary hyperaldosteronism due to bilateral adrenal disease( $)^{()}$. The place of a similar therapeutic option in secondary hyperaldosteronism remains a possibility as MR antagonist will block the site of action of elevated aldosterone levels ${ }^{(10)}$. Renin inhibitors are another option as they inhibit the activity of renin and block the downstream effects that lead to elevated blood pressure ${ }^{(11)}$. The index patient was successfully treated with ketoconazole, which is a steroidogenesis inhibitor. Ketoconazole controlled her hypercortisolism as well as her resistant hypertension. Following surgery her blood pressure was normalized without any antihypertensive medication. Thus, successful treatment of the primary pathology may alleviate the elevated blood pressure contributed by secondary hyperaldosteronism as in our patient.

\section{Conclusions}

We describe a patient who presented with Cushing's syndrome and secondary hyperaldosteronism due to an adrenal adenoma who was successfully treated with unilateral adrenalectomy. The coexisting secondary hyperaldosteronism in Cushing's syndrome can culminate in resistant hypertension. Specific management of secondary hyperaldosteronism has not been extensively investigated, yet medical treatment of Cushing's syndrome, MR antagonists or renin inhibitors may play a role and extensive future studies are warranted. Definitive therapy includes the treatment of the primary pathology, which was laparoscopic left adrenalectomy of the index patient.

\section{Declarations}

\section{Ethics approval and consent to participate}

Patient's consent was taken to report her clinical details anonymously

\section{Consent for publication}

We have taken the informed written consent from the patient to report and publish about her illness anonymously.

\section{Availability of data and material}

Clinical details and results of investigations are documented in the clinic records and bed head tickets. Bed head tickets are available in the record room of National Hospital of Sri Lanka. Most of the original reports and clinic records are with the patient.

\section{Competing interests}

The authors declare that they have no competing interests

Funding

Not needed. 


\section{Authors' contributions}

I Ranathunga and N P Somasundaram were involved in the history taking, examination, diagnosing and management of patient's condition and prepared the manuscript for publication.

All authors read and approved the final manuscript.

Acknowledgements

None.
List of abbreviations

$\begin{array}{ll}\text { ACTH } & \text {-Adrenocorticotrophic hormone } \\ \text { ODST } & \text {-Overnight dexamathazone suppression test } \\ \text { LDDST } & \text {-Low dose dexamathazone suppression test } \\ \text { HDDST } & \text {-High dose dexamathazone suppression test } \\ \text { ARR } & \text {-Aldosterone/ Renin ratio } \\ \text { CT } & \text {-Computerized tomography } \\ \text { MR } & \text {-Mineralocorticoid receptor }\end{array}$

\section{References}

1. Nieman LK, Biller BMK, Findling JW, Newell-Price J, Savage MO, Stewart PM, et al. The Diagnosis of Cushing's Syndrome: An Endocrine Society Clinical Practice Guideline. J Clin Endocrinol Metab [Internet]. 2008;93(5):1526-40. Available from: https://doi.org/10.1210/jc.2008-0125

2. Hobma S, Hermus A, Pieters G, Smals A, Kloppenborg P. Concurrent hypercortisolism and hyperaldosteronism due to an adrenal adenoma. Klin Wochenschr. 1990;68(19):981-3.

3. Kawai M, Sahashi K, Yamase H, Kishida Y, Sumida K, Kawamura K. Renin-producing adrenal tumor: report of a case. Surg Today. 1998;28(9):974-8.

4. Nicolis G, Amsel B, Yorfr N, Mount T. Pathogenesis of Hypertension in Cushing's Syndrome. 1975;58(February).

5. Krakoff LR. Measurement of plasma renin substrate by radioimmunoassay of angiotensin. I. Concentration in syndromes associated with steroid excess. J Clin Endocrinol Metab. 1973 ;37(1):110-7.

6. Saruta T, Suzuki H, Handa M, Igarashi Y, Kondo K, Senba S. Multiple factors contribute to the pathogenesis of hypertension in Cushing's syndrome. J Clin Endocrinol Metab. 1986;62(2):275-9.

7. Kidney JC-H and the, 1963 undefined. Effects of adrenocortical steroids on active sodium transport by the urinary bladder and ventral skin of amphibia. Acad Press New York.

8. Nieman LK, Biller BMK, Findling JW, Murad MH, Newell-Price J, Savage MO, et al. Treatment of cushing's syndrome: An endocrine society clinical practice guideline. J Clin Endocrinol Metab. 2015; 100(8):2807-31.

9. Brown JJ, Davies DL, Ferriss JB, Fraser R, Haywood E, Lever AF, et al. Comparison of surgery and prolonged spironolactone therapy in patients with hypertension, aldosterone excess, and low plasma renin. Br Med J [Internet]. 1972;2(5816):729-34. Available from: https://pubmed.ncbi.nlm.nih.gov/4338668

10. Sica DA. Mineralocorticoid Receptor Antagonists for Treatment of Hypertension and Heart Failure. Methodist Debakey Cardiovasc J [Internet]. 2015;11(4):235-9. Available from: https://pubmed.ncbi.nlm.nih.gov/27057293

11. CV Pharmacology | Renin Inhibitors [Internet]. [cited 2020 Jun 15]. Available from: https://www.cvpharmacology.com/vasodilator/renin 